\title{
LOS VERDADEROS ÚLTIMOS DE FILIPINAS
}

\section{THE REALLY LAST OF PHILIPPINES}

\section{AUTOR}

\section{Juan Jiménez Mancha}

Historiador. Articulista en varias publicaciones científicas y divulgativas (España)

juanjimenez@hotmail.com

\section{RESUMEN}

Una de las consecuencias de la guerra contra Filipinas fue el abandono de miles de antiguos colonos españoles (soldados, funcionarios, sacerdotes, etc.) en las islas. Por una parte se encontraban desamparados por del Gobierno español, que emprendió acciones de rescate muy tarde, y por otra eran repudiados por los propios filipinos que veían en ellos a sus antiguos opresores. Las cláusulas exigidas para su repatriación eran muy duras y también lentas y, aunque algunos pudieron escapar, la mayor parte de los prisioneros no fueron repatriados hasta 1900.

\section{PALABRAS CLAVE}

Prisioneros españoles- Repatriación- Aguinaldo- Independencia filipina.

\section{ABSTRACT}

One of the consequences of the war against the Philippines was the abandonment of thousands of Spanish colonists (soldiers, officers, priests, etc.) in the islands. On the one hand were abandoned by the Spanish government, that took action to rescue 


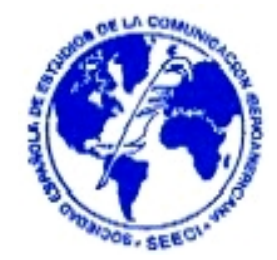

very late, and the other hand was repudiated by the Philippines who saw them to their former oppressors. The terms required for return were very hard and slow, although some escaped, most of the prisoners were not repatriated until 1900.

\section{KEY WORDS}

Spanish prisoners - Repatriation - Aguinaldo - Philippine Independence.

\section{ÍNDICE}

1. Introducción.

2. La situación de los cautivos.

3. El camino hacia la repatriación.

4. Conclusión.

5. Bibliografía.

Al finalizar la guerra en suelo tagalo entre España y los Estados Unidos, se originó la extraña circunstancia de que alrededor de 13.000 españoles, entre soldados, civiles y frailes, quedaban como prisioneros en manos de los filipinos. Los afectados, como sus familias, pensaron que se trataba de una situación pasajera a la que pronto alguien daría solución. Pero no ocurrió así. El cautiverio de estos prisioneros de una guerra ya acabada se prolongará, en la mayoría de los casos, durante años y medio. 


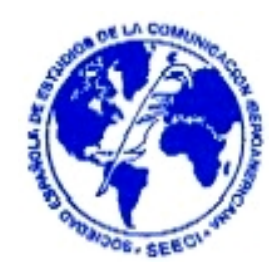

\section{Introducción.}

Una vez más la historia de los perdedores de una guerra recibieron el desprecio y el olvido de toda la sociedad, pero con el agravante del largo y angustioso encierro en tierras remotas, queridas y recientemente arrebatadas. Las bocas de los testigos se llenaros de buenas palabras y esperanzadoras intenciones, pero nadie arriesgó su posición por enmendar el destino de unos seres abandonados a su suerte ¿Dónde quedó el honor con tanta pasión defendido como valor supremo de la patria? La nación se hundía, y la repatriación de los españoles en Filipinas se presumía gravosa para las maltrechas arcas del Estado. No importaba si se demoraba un tiempo. Las autoridades filipinas deberían haber puesto en libertad a estas personas una vez abandonadas las armas, pero nada ni nadie les empujó a actuar en este sentido. Llegaron incluso a argumentar que no apreciaron interés en alguno de los máximos gobernantes españoles. Exageraron muy poco. Por su parte los Estados Unidos, supuesto paladín de los derechos humanos, apenas se preocuparon por un tema para ellos menor y ajeno. La opinión pública de los países occidentales parecía pedirles, sin embargo, una acción liberalizadora. En octubre de 1898 el General Ottis, Comandante en jefe de las fuerzas estadounidenses de ocupación en Manila, envió una carta a Aguinaldo solicitando la libertad de la totalidad de españoles prisioneros. El líder revolucionario contestará, también a través de carta, exponiendo los motivos de tan atípica retención.

Aguinaldo sólo hablará del pasado. Así, se alegaba que los funcionarios civiles españoles eran voluntarios armados, que en ocasiones llegaron a torturar y fusilar a ciudadanos filipinos. Ahora no cabía el perdón. En cuanto a los clérigos, se les acusaba de ser creadores de grandes colonias agrícolas, conducidas de una manera egoísta y en contra de las necesidades de las clases más humildes. Aguinaldo, especialmente duro con ellos, defendía que bajo la máscara de la cura de almas se escondía el afán por enriquecerse y hacerse dueños absolutos de las vidas, hacienda y honor filipinos. En la carta se decía que con el encarcelamiento de civiles y frailes 
se daba satisfacción a una vital exigencia del pueblo tagalo. Finalmente, la retención de soldados se justificaba con el mantenimiento en cárceles españolas de ciudadanos filipinos. El General Ottis volvió a insistir enviando otro escrito en donde se apelaba con mayor viveza a los derechos humanos y a las normas internacionales vigentes. De nuevo la respuesta de Aguinaldo fue negativa.

\section{La situación de los cautivos.}

No hay unanimidad sobre el trato recibido por los cautivos durante aquel período. En España no se sabía apenas nada sobre el acontecer diario de aquellas personas. Filipinas estaba demasiado lejos. Los testimonios dejados por los propios reos reflejan contradicciones en bastantes casos. Del análisis de los mismos podemos concluir que las condiciones de vida que padecieron variaron mucho en virtud de tres factores: el paso del tiempo (el trato fue de mejor a peor según mermaban las posibilidades económicas del ejército revolucionario), las provincias (pues la simpatía 0 afecto hacia el pueblo español era muy diferente según la localidad), y el jefe insurrecto que mandase en la zona (en virtud de sus cualidades humanitarias).

Es justo reconocer, hablando en general, un esfuerzo inicial de gran parte del pueblo filipino. Los vínculos de amistad y de sangre pesaban lo suyo, aunque hubo quienes se recrearon en sentirse superiores a la nación antes dominadora. En un gran número de poblaciones se obligaba a los prisioneros a trabajar en la construcción de carreteras, cavando trincheras, talando árboles o arreglando y limpiando caminos y calles. En algunos pequeños pueblos pudieron, sin embargo, gozar durante el día de una casi completa libertad de acción. Otras localidades optaron por el riguroso encierro en improvisados e inhóspitos sitios, sin siquiera camas, y en ocasiones bajo estricta vigilancia. Algunos testimonios nos hablan de que bastantes personas fueron despojadas de todas sus pertenencias. Las ayudas materiales dependían también de las jefaturas y de los recursos manejados. 


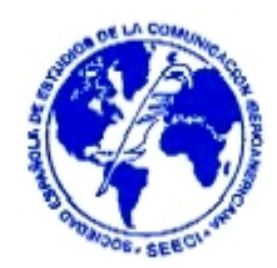

En los primeros meses se pagaba diariamente una pequeña cantidad de dinero en metálico, así como cerca de una libra de arroz. Pero pronto escasearon los socorros, agravándose las condiciones físicas y psicológicas de unas personas víctimas no sólo del hambre, la miseria y la cárcel, sino que también, y conviene no olvidarlo, de la derrota en la guerra y de un destino ilógico que jamás pudieron entender. Muchos, los más necesitados, se empeñaron en reclamar sin éxito los fondos que tenían depositados en Manila, o sus pagas como soldados o funcionarios españoles. Pero nunca desde instancia estatal alguna se les hizo llegar dinero, pese a la posibilidad de canalizar los abonos a través de las autoridades de Manila. Algunos jefes militares ayudaron económicamente a los soldados más necesitados. En verano de 1899, aproximadamente al año de prisión, se llegaron a registrar casos hasta de venta de cautivos, a estas personas se las dispensó un trato similar al de los esclavos. Los sufrimientos se agudizaron aún más a raíz de los continuos traslados de localidad a que fueron expuestos, en ocasiones recorrieron descalzos a pie varias decenas de kilómetros durante largas y penosas jornadas. Los lazos de hermandad también afectaron a altas instituciones del ejército revolucionario, varios jefes de las tropas de Aguinaldo dictaron severos castigos hacia todo aquel filipino que ofendiera a algún prisionero. Otros llegaron incluso a cobijar en sus hogares, durante meses, a bastantes oficiales. Numerosos soldados lograron escapar gracias a la ayuda de filipinos amigos, familiares o solidarios con los españoles.

Como consecuencia de estas fugas Aguinaldo dictó un decreto el 5 de noviembre de 1898 en donde se amenazaba con veinte años de cárcel, se decía que por traición, a todo aquel que ayudase a huir a algún prisionero de guerra. A su vez, se ordenaban nuevos traslados en busca de reconcentraciones en puntos claves de cada provincia. Con estos reagrupamientos se perseguía un mejor control y orden en las retenciones, además de una presumible reducción en las posibilidades de evasión. Aguinaldo estableció por entonces las siguientes condiciones para la entrega a España de militares y civiles:

10. Se abrirán negociaciones formales entre España y el gobierno nacional filipino, nombrando España un delegado para tratar con el gobierno filipino. 
2ํ.. España libertará y repatriará:

- Todos los filipinos retenidos como prisioneros en la península o en los presidios de África, por hallarse directa o indirectamente complicados con la insurrección, y del mismo modo los que se hallan confinados por igual concepto en Las Carolinas, Mindanao, J oló, Paragua, etc.

- Todos los prisioneros de guerra, tanto civiles como militares, condenados como traidores, revolucionarios o desertores, por haber secundado en cualquier sentido el movimiento filipino hacia la independencia durante este siglo.

- La libertad de estos prisioneros se ha de verificar antes que los filipinos entreguen a los españoles que tienen en su poder. España, además, concederá una amnistía general y plena para todos los españoles y filipinos que hayan sido acusados de complicidad con la rebelión.

3o. España pagará todos los gastos de repatriación de los filipinos que tienen prisioneros, y pagará también los gastos de manutención y repatriación de los españoles prisioneros de los filipinos. Estos pagos se consideran como una indemnización de guerra. El gobierno nacional filipino consentirá en pagar los gastos de repatriación de los filipinos.

La principal exigencia de Aguinaldo radicaba pues, en teoría, en la liberación de los varios cientos de filipinos confinados en cárceles de la península ibérica y el norte de África. El gobierno español estaba incurriendo en el grave error político de no ponerlos en libertad, medida que materializará varios meses más tarde, ya a destiempo.

Aguinaldo consideraba que los frailes prisioneros eran un caso aparte, ya que, según él, habían actuado como agentes del Papa. La entrega tenía que ser negociada con el Sumo Pontífice, estableciéndose las siguientes condiciones:

1․ Que un delegado apostólico demande su libertad en nombre del Papa. 
2․ Que todas las bulas y decretos pontificios concediendo privilegios especiales a las órdenes religiosas, contra las leyes o reglas generales de la I glesia, sean abolidos.

3․ Que todos los derechos del clero secular sean respetados.

40. Que los frailes no puedan desempeñar ningún cargo parroquial, catedral, episcopal o diocesano.

50. Que todos los cargos parroquiales, catedrales, episcopales o diocesanos hayan de ser desempeñados por individuos del clero secular filipinos o naturalizados.

60. Que se fijen reglas para la elección de los obispos. Podrá celebrarse un concordato con el Vaticano sobre las bases de estas condiciones.

Los filipinos empezaban a pensar políticamente como una nación ansiosa de su independencia real.

Los frailes no gozaban de las simpatías de la mayor parte del pueblo por ellos mismos colonizado. Sus criterios feudales, empleados a lo largo de muchos años, impulsaron el crecimiento de las ansias independentistas. Las cinco órdenes más extendidas, y ahora castigadas, eran las de los dominicos, agustinos, jesuitas, franciscanos y recoletos. Las condiciones de vida que sufrieron durante el cautiverio fueron especialmente duras. En ocasiones se practicaron con ellos torturas y humillaciones públicas hasta llevarlos a la muerte.

Pero también, al igual que en el caso de soldados y civiles, recibieron la ayuda de un gran número de filipinos incapaces de olvidar de golpe los lazos de amistad, y en este caso espirituales. Muchos soldados que custodiaban frailes se acercaban a ellos para darles dinero, ropa o comida, en nombre de otra gente 0 de su propia familia. Las mismas órdenes religiosas trabajaron sin desmayo en socorro de sus propios integrantes.

Todos los prisioneros escribieron multitud de cartas a diferentes instituciones y autoridades, tanto de la península como, sobre todo, de Manila. Lo más solicitado eran medicinas, ropas, calzado, 0 al menos parte de sus pagas como soldados 0 
funcionarios. El gobierno liberal de Sagasta, dejó escapar los momentos que rodearon a la firma del Tratado de París, el 10 de diciembre de 1898; pese la humillación sufrida en los campos de batalla y en los despachos parisinos, al gobierno español le correspondía exigir la rápida puesta en libertad de todos los prisioneros de guerra, pero pudo más el miedo a McKinley y el deseo de salvaguardar otros intereses.

Así, antes de que concluyera el fatídico año sólo cabe destacar la labor de socorro promovida por el Casino Español de Manila, bajo la dirección de su presidente, Antonio Fuset. El propio Casino encabezó la suscripción con 5.000 duros, obteniéndose a los cuatro meses la cantidad de 26.000 pesos. Muchos fondos llegaban a Manila vía Madrid, pero tanto tardaban en recalar en el Casino que el propio Fuset se tuvo que personar en la capital española para acelerar los envíos. El Casino también intentó que el General Primo de Rivera cediese como subscripción el dinero que le adeudaba el Estado, 80.000 pesos recaudados como subscripción popular, como premio a su tarea de pacificación de las islas, en gestión previa a la guerra hispano-norteamericana. Pero el Casino fracasó en su empeño provocando además la indignación del célebre General, quien llegó a difundir en prensa un comunicado donde exponía lo siguiente:

"Madrid, 22 de noviembre de 1898.

Sr. Director de El Imparcial:

Muy señor mío. Con la firma anónima de Varios españoles aparece hoy un telegrama en su periódico, en que se habla de que hoy ceda los 80.000 pesos de la subscripción hecha a mi favor en Filipinas para los que sufren prisioneros de los tagalos. Aparte de que sobre esto he dicho cuanto debía y donde debía, comprenderá $V d$. que mi respetabilidad me impide hacer el juego a cuatro desocupados, que por lo visto, tratan de constituirse en mis administradores.

Lamentando como el que más la situación de los prisioneros, 
comprendo la ineficacia del sistema que se trata de seguir, pues no es de recursos seguramente de lo que carecen, sino de medios de emplearlos o de consentimiento para hacerlo por parte de sus indignos opresores."

Desde los periódicos españoles, y desde muchos extranjeros, se seguían los acontecimientos de Filipinas con gran atención, en especial lo relacionado con la suerte de los prisioneros españoles. La Época, El Imparcial, El País, Heraldo de Madrid, El Nacional, etc., destacaron por sus ataques a Sagasta y a su gobierno, alertando acerca de su escasa dedicación y habilidad para tratar tan grave asunto.

A primeros de Enero de 1899 llegaba a Manila, en calidad de Capitán General de las islas, el General Diego de los Ríos, con la misión principal de obtener la rápida liberación de los prisioneros. Con él se iniciaba una larga serie de gestiones cuyo final siempre derivó en fracaso, y en donde la mediocridad y la falta de interés real fueron una constante entre políticos y partidos. Numerosas instituciones de variada índole decidieron involucrarse en los acontecimientos con actuaciones humanitarias, como es el caso de la Sociedad I bero-Americana o el Banco Filipino.

El 4 de Enero Ríos enviaba el siguiente telegrama, de tono pesimista, al gobierno de Madrid:

"La situación gravísima de los americanos con respecto a los insurrectos imposibilita gestiones sobre prisioneros que pudieran ser contraproducentes; pero puede el Gobierno tener la seguridad de que haré cuanto sea posible para buscar la solución que V.E. me recomienda."

Los revolucionarios filipinos preparaban la sublevación contra el ejército norteamericano. El 15 de Enero publicaba El Imparcial un nuevo ataque al gobierno español: 
"Con argumentos irrebatibles censura La Época el escaso celo que ha demostrado el Sr. Sagasta al ocuparse de la liberación de nuestros desdichados hermanos de Filipinas. Todo han sido indecisiones, artificios, aplazamientos, digámoslo de una vez "mentira y burla de la nación" en el Sr. Sagasta y su gobierno, en ese tristísimo asunto del rescate o libertad de los prisioneros españoles en Filipinas. Mientras duraron en París las negociaciones para la paz, se escudó el primero y disculpó su inacción alegando que el tratar del rescate podría prejuzgar otros asuntos graves. Y como para el Sr. Sagasta el tropezar con una excepción dilatoria, o con una argucia, por pobre que sea, equivale a una patente para dormir despierto y para la absoluta inacción, no hay que decir que desde el primero de octubre de 1898 al 10 de diciembre nada se intentó en Filipinas, ni aún una estadística aproximada de los prisioneros, ni aún el envío de algunas cantidades al Casino de Manila. Desde el 10 de diciembre último, fecha de la firma del protocolo, desaparecía el pretexto, alegado antes, del temor de disgustar a McKinley y a los comisarios norteamericanos."

Pocos días después, sin embargo, se produjo la ansiada sorpresa de la puesta en libertad de los soldados enfermos y de una gran parte del personal civil. La noticia llegó al Ministerio de la Guerra gracias a un telegrama recogido el 24 de enero:

"... hoy 23 de enero ha sido concedida libertad a todos los prisioneros civiles y militares, enfermos o inútiles, esperando poder comunicar en breve análoga noticia respecto militares sanos."

La información causó una enorme satisfacción en la opinión pública. Varios días más tarde aparecían en algunos diarios las primeras estadísticas de civiles liberados, así como del personal que aun se hallaba en poder de los filipinos, al menos 9.000 individuos. 


\section{El camino hacia la repatriación.}

El 5 de febrero se desataba la guerra entre los Filipinos y los Estados Unidos. España, que había renunciado definitivamente a las islas con el Tratado de París, se veía abocada a ser testigo impasible de aquella lucha tan desigual. Su posición resultaba insólita y dolorosa. Por otra parte, en los más altos jefes revolucionarios se había ido desarrollando la idea de que la retención de aquellos desdichados proporcionaba un valor cara al futuro, una garantía ante las eventualidades del porvenir. Con la nueva guerra se truncaron de un modo brusco las esperanzas de liberación de los prisioneros. A los filipinos sólo les interesaba ahora conseguir armas, munición o dinero a cambios de cautivos, mientras que los Estados Unidos se mostraban decididos a evitar cualquier trueque que pusiera en peligro sus planes de expansión. Pese a todo, desde España se observaba el nuevo conflicto irradiando ánimos hacia el pueblo filipino, y el lógico odio hacia el ejército verdugo y pesadilla de la nación. Ambos sentimientos operaron como filtros de toda información llegada de las islas.

El 22 de febrero se firmaba en Madrid, al fin, un Real Decreto concediendo el indulto a los filipinos confinados en presidios de la Península y el Norte de Africa, vieja exigencia de Aguinaldo para negociar la libertad de los presos españoles. Pero ahora los jefes filipinos, como acabamos de ver, tenían otras necesidades. La situación de los prisioneros se fue así eternizando. El General norteamericano Ottis se opuso sistemáticamente a que el General Ríos negociase con el gobierno filipino, siempre con el argumento de que si éste recibía sólo dinero lo emplearía en armas o municiones. A los filipinos no les importaba las molestias y gastos ocasionados por la vigilancia y mantenimiento de los prisioneros. Las dificultades norteamericanas se conocieron oficialmente en España a raíz de un nuevo telegrama de Ríos recibido el 12 de marzo:

"General Ottis impide gestión prisioneros. Manifiesta que estando filipinos en guerra con americanos no puede permitir rescate sobre 
base recursos metálicos que mejorarín situación aquí; no permite comisionados atravesar líneas avanzadas. Protesto alegando sentimientos humanitarios, $y$ en nombre de estos creo llegado momento gestionar oficios potencias por mediación cónsules."

El mensaje llegado de Manila provocó una urgente entrevista entre Silvela -nuevo presidente del Gobierno- y el General Polavieja, profundo conocedor de la causa filipina. Se decidió desechar negociar con Aguinaldo por miedo a los norteamericanos, como alternativa se determinó recurrir a la vía diplomática. De este modo, Ríos convocaba a una reunión en Manila a los principales representantes extranjeros y a las personas de mayor influencia en las islas. En el encuentro se nombró una comisión internacional que iría a hablar con Aguinaldo en su misma residencia, entregándole una carta firmada por el elemento extranjero del archipiélago, incluido las más importantes industrias y casas de comercio. En la carta se pedía la liberación de prisioneros por motivos humanitarios. Sánchez Ocaña, Jefe de Estado Mayor de Ríos, y el auditor de la brigada Octaviano Romeo, fueron elegidos como representantes, aunque el encargado de llevar a Aguinaldo el documento con las firmas fue el Barón Du Marais. El jefe filipino jamás recibió este escrito al ser matado el emisario francés en plena misión.

El 6 de abril llegaba a Madrid un telegrama del Casino Español de Manila, en donde se daba cuenta del nuevo fracaso de una misión negociadora, en este caso formada por aquel centro.

Poco después, el 20 del mismo mes, el General Ríos mandó otra delegación encabezada de nuevo por el auditor de brigada Octaviano Romeo, ahora acompañado por el Comandante de Ingenieros Las Heras. Ambos llegaron a Malolos y pudieron entrevistarse con el General Mc Arthur, pero el jefe norteamericano les obligó a desistir de su empeño prohibiéndoles el cruce de sus líneas.

Romeo y Las Heras repetirán la empresa el 25 de abril, acompañados por Armando Alvares, alto cargo de Tabacalera que representaba a la colonia extranjera, y el 
influyente periodista José Gómez Centurión, el cual tenía dos hijos militares como prisioneros. Esta vez se logró atravesar las líneas norteamericanas, pero las tropas filipinas se opusieron a que continuaran su camino hasta Aguinaldo. Tan sólo obtuvieron de éste un telegrama difícil de entender políticamente:

"Estando en negociaciones con el gobierno americano respecto a la libertad de los prisioneros españoles, no puedo entablar negociaciones de ninguna clase con el Gobierno de España."

La única explicación a este sorprendente mensaje radica en una nueva ingenua pretensión filipina: Aguinaldo y sus consejeros pensaban ahora que los prisioneros les serían de utilidad para negociar una paz honrosa con los norteamericanos. ¡Cómo si a estos últimos les importase en algo la suerte de aquellos pobres! Ríos apostó entonces por hacer llegar a Aguinaldo a alguna personalidad de su entera confianza. De esto modo se envió, bajo el permiso del General Ottis, al escritor y periodista español José María Romero y Salas, residente en Filipinas desde bastantes años atrás, y director del Diario de Manila y el Diario de Filipinas. También marchaba en la expedición Isaac Fernández de los Ríos. Pero en este caso las tropas americanas imposibilitaron el paso de los comisionados, provocando su regreso a Manila aduciendo motivos de alta política. Romero y Salas marchará a Hong-Kong donde fundará, lejos de la censura estadounidense, el Correo de Oriente, periódico portavoz de la opinión de los españoles que aún quedaban en las islas.

A primeros de junio el General Jaramillo sustituía a Ríos en su cargo. Bajo la nueva dirección se persistirá en la postura errónea de delegar en otros las delicadas tareas de gestión, pese a que Aguinaldo siempre se escudó, para esquivar negociar, en la poca representatividad de las personas comisionadas. Pero tampoco Jaramillo, como Ríos, expondrá la vida en el trabajo encomendado. La primera delegación formada por el nuevo Capitán General estará encabezada por Antonio del Río y el Comandante Enrique Toral. El General Ottis les autorizó a cruzar las líneas. Los emisarios partieron hacia el campo filipino el 15 de junio. Durante varios días de negociación, al fin, con Aguinaldo y otros jefes filipinos, los cuales afirmaron que 
pondrían en libertad a todos los prisioneros menos a los frailes, excepción que no pudo ser aceptada. El gobierno filipino comunicó entonces que se admitía la liberación de todos los prisioneros sin exclusión alguna, pero con dos condiciones:

1o. El reconocimiento de la independencia filipina y de que la cesión hecha por España de su soberanía a Filipinas a la nación americana carecía de todo valor.

2ํ. Aceptado esto, el gobierno filipino se comprometía a sufragar todos los gastos de repatriación de los prisioneros españoles, pero se tenía que pagar por su libertad en armas, municiones, provisiones o en su equivalencia en metálico.

El primer requisito sólo pudo calificarse como un disparate, mientras que para el pago, lógicamente en dinero, era imprescindible burlar la oposición norteamericana. Tras varias jornadas de diálogo los filipinos estipularon el canje en 7 millones de pesos, cifra que a los españoles les pareció desorbitada, ofreciendo varios días después, como alternativa, la suma de 2 millones. Las negociaciones se interrumpieron, pero en un tono amistoso. Justo por aquellas fechas, el 30 de junio, Aguinaldo firmaba el famoso decreto otorgando la libertad a los héroes españoles de Baler, no considerándolos, por tanto, prisioneros de guerra. La hazaña de una treintena de hombres, en el futuro conocidos como los últimos de Filipinas, fue dejando a un lado el interés por la angustiosa situación de unas 9.000 personas aún injustamente cautivas. Los soldados del glorioso destacamento eran puestos a disposición de los comisionados españoles. Desde mayo se hablaba en la península cada vez más de Baler, y menos de los hombres que aún quedaban en Filipinas. En la prensa llegó a desaparecer el ya viejo tema de los prisioneros. El gesto de Aguinaldo otorgando la libertad a aquel puñado de soldados fue exageradamente aplaudido en España. Nadie se acordó de los miles de presos todavía en manos filipinas.

A primeros de agosto el General Jaramillo conocía un nuevo decreto firmado por Aguinaldo el 5 de junio. En dicho texto se concedía la libertad a mas prisioneros 


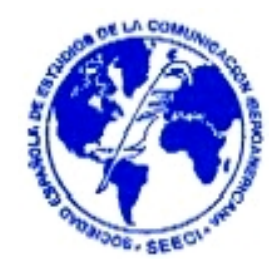

civiles y militares enfermos, indicándose el procedimiento a seguir para hacer efectiva la liberación.

Las autoridades españolas se apresuraron a reemprender las negociaciones para liberar a todos sin exclusión, pero se suspendieron las mismas por orden del gobierno de Madrid, al parecer por presión norteamericana ante la sospecha del trueque por dinero. Las gestiones españolas apuntaron de nuevo hacia el bando norteamericano. Jaramillo pidió permiso al General Ottis para llevar víveres a los prisioneros españoles, e incluso para recogerlos bajo bandera de la Cruz Roja, pero la respuesta fue negativa.

A finales de septiembre Del Río y Toral retornaron a negociar, llevando en la mano unas bases sobre las cuales llegar a un definitivo acuerdo. Los jefes filipinos rechazaron el intento alegando, una vez más, falta de representatividad en los comisionados españoles. Tras varias nuevas entrevistas se decidió concertar un encuentro entre ambos bandos para el 2 de octubre. Llegado aquel día el Gobierno filipino insistió otra vez en la necesidad del pago de los 7 millones de pesos, así como en el reconocimiento de su soberanía en las islas. Las conversaciones concluyeron con estas irónicas palabras de los comisionados de Aguinaldo:

"El gobierno filipino no retiene por placer ni gusto a los prisioneros españoles ni obstaculiza su liberación, sino que pretende sola y exclusivamente sacar de este asunto las ventajas que le proporcionan sus derechos, conveniencias e intereses."

Los delegados españoles vieron como se les daba el pasaporte para abandonar el territorio filipino. Aguinaldo y sus colaboradores evidenciaban un gran nerviosismo ante los enormes avances de las tropas norteamericanas. Las carencias humanas y materiales empujaron a Aguinaldo a dictar otro decreto en donde ofrecía entregar a los prisioneros al gobierno norteamericano, pero los Estados Unidos hicieron caso omiso y continuaron acorralando al ejército filipino. Aguinaldo se vio obligado a diseminar sus fuerzas, hecho que favoreció el abandono de los prisioneros, los cuales 


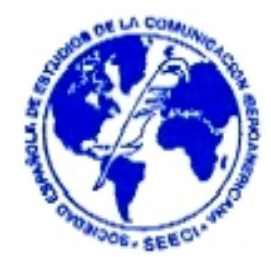

ya eran sólo un estorbo. De esto modo, la mayoría de confinados en el norte y centro de la isla acudieron a los campamentos americanos para allí tomar de los comisionados españoles un poco de dinero en metálico y algo de calzado y ropa.

Se reencontraban con la libertad, pero no tenían que agradecérselo a nadie. Las circunstancias, antes crueles con estas personas, se ponían ahora de su parte. Al ejército filipino no le interesaba ya aquella retención, ni era capaz de atenderla. Pese a que el feliz desenlace sólo fue producto de la casualidad, muchos españoles pretendieron adjudicarse el mérito de una supuesta gestión definitiva. Por entonces abundaba la enfermiza necesidad de afanarse en edificar héroes contemporáneos, con los que compensar en el ánimo el declive del país. De este modo, muchos elevaron a la categoría de gesta la labor de Jaramillo, otros la de Ríos y otros la de Antonio Fuset, Presidente de la Comisión Ejecutiva de esta institución, como héroe responsable en París de las conversaciones finales que desencadenaron la liberación.

Precisamente la revista La Cruz Roja, subtitulada órgano oficial de la Asamblea Suprema española, realizará un seguimiento detallado de los pasos de los recién liberados, dando cuenta de la llegada de buques y de los socorros dispensados en los puertos para paliar su lamentable estado. Desde una revista disidente de la Cruz Roja, titulada El Camillero, se mantendrá una tarea informativa similar. Pero la publicación más original y en exclusiva dedicada al tema que nos ocupa fue Los Prisioneros, nacida como periódico auxiliar de la asociación de las familias de los prisioneros en Filipinas. Se trataba tan sólo de una página editada con periodicidad irregular, pero que fue portavoz de toda clase de noticias y quejas en torno a la realidad y futuro de los prisioneros. Desde sus columnas se intentó presionar tanto a las Cortes, como a la prensa, opinión pública e incluso al pueblo filipino. En ella se divulgarán las relaciones completas de liberados, indicando sus nombres, cargos y lugares en donde se hallaban. La revista, editada en Madrid, duró, que sepamos, desde el 29 de octubre de 1899 al 7 de enero del año siguiente, posiblemente sólo cinco números; pero pese a su efímera existencia aporta unos datos extraordinariamente valiosos y cargados de emoción, producto de la indignación e 


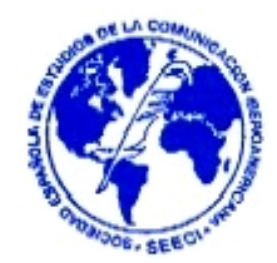

impotencia de los familiares afectados. El director y el principal redactor responsable, Luis García Arias y Andrés de Lovaine respectivamente, fueron citados a juicio por una demanda interpuesta por la Cruz Roja, al cuestionar el buen fin del dinero que se recaudaba para obras benéficas. I gual suerte corrieron los responsables de El Camillero. Otras revistas irrepetibles que atenderán al tema de los prisioneros serán Filipinas ante Europa, conocida como el periódico de Aguinaldo, pero también editado en Madrid, y cuya dirección corrió a cargo del filipino I sabelo de los Reyes y Florentino, personaje de compleja trayectoria pero fundamental para entender la Historia de Filipinas. También en Barcelona surgirá El Filipino, periódico que era órgano del subcomité filipino de Barcelona. Sus características ideológicas fueron similares a las de Filipinas ante Europa, su director era Manuel Artigas y Cuerva, responsable también de la creación y dirección, junto a Eduardo Castañer, de la Voz de Ultramar, otro ejemplo de publicación singular de consulta obligada para el historiador.

¿Qué importa que perezcan en Filipinas unos cuantos miles de españoles?, se había preguntado El Imparcia/ varios meses atrás (11 de enero de 1899). También desde este diario se señalará dos días más tarde:

"España no puede dar al mundo, después de tantas amarguras y de tan grandes vergüenzas como las que últimamente ha sufrido, el espectáculo de una nación que ha perdido el más grande y el más fuerte de todos los sentimientos: el sentimiento de la maternidad."

Entre diciembre y enero de 1900, regresaba la gran mayoría de los supervivientes, unas 6.000 personas, bastantes dadas por muertos por sus familiares. La cifra había decrecido porque en los últimos meses muchos fallecieron víctimas de enfermedades. La repatriación se efectuó a través de grandes buques, como el San Ignacio, Elcano o el León XIII, algunos embarques fueron sufragados por los Estados Unidos ¿Sentimiento de culpabilidad?

\section{Conclusión.}


Ni Silvela ni Sagasta, ni personalidad alguna con verdadero poder, se libraron de la vergüenza de un olvido tan injusto como innoble, tan "poco español", si nos atenemos a los conceptos que tanto gustaban en la época. En todos los diarios aparecieron de una forma continuada los nombres de los ocupantes de cada barco de repatriación. Las llegadas de los mismos se procuraban llevar a cabo de una manera sigilosa, a ser posible entre las tinieblas de la noche, como había sucedido en el caso de los repatriados de Cuba. Fueron los últimos en volver a casa, aunque muchos se encontraron sin hogar y se resignaron a vagabundear por el país. Nunca pasaron del anonimato, pero en verdad les cabe el honor, puesto que así quiso el destino, de ser realmente los últimos de Filipinas, sin cuestionar el papel tradicionalmente asignado de los héroes de Baler, a los que también les tocó vivir el olvido tras un ruidoso recibimiento.

\section{Bibliografía}

Diarios:

La Época, Heraldo de Madrid, El Imparcial, El LIberal, El Nacional, El País.

Revistas:

El Camillero, La Cruz Roja, Filipinas ante Europa, El Filipino, Nuestro Tiempo (Rubiano, Santos, Recuerdos de un prisionero de los tagalos, Oct. y Dic. 1907; Feb. y Sept. 1908), Los Prisioneros, La Voz de Ultramar.

Anuarios: 
SOLDEVILLA, Fernando: El año político, volúmenes de 1898 y 1899, Madrid, 1899 y 1900.

Libros:

GENOVA E ITURBE, Juan: Los prisioneros, memoria de la comisión desempeñada en el campo filipino por D. José Génova e Iturbe, de orden del Excelentísimo Señor Capitán General de Filipinas, D. Diego de los Ríos, Madrid, Establecimiento tipográfico de G. Juste, 1900.

HERRERO SAMPEDRO, Ulpiano: Nuestra prisión en poder de los revolucionarios filipinos, crónica de dieciocho meses de cautiverio de más de cien religiosos del centro de Luzón, empleados en el ministerio de las almas, Manila, Imprenta del Colegio de Santo Tomás, 1900.

MARTíneZ, Graciano: Memorias del cautiverio, Manila, Imprenta del Colegio de Santo Tomás, 1900.

MORENO JEREZ, Luis: Los prisioneros españoles en poder de los tagalos, relato histórico de este cautiverio y de las gestiones llevadas a cabo para libertarlos. Manila, Establecimiento tipográfico del Diario de Manila, 1900.

RÍA-BAJA, Carlos: El desastre filipino: memorias de un prisionero. Barcelona, Tipográfica La Académica, de Serra Hermanos y Russell, 1899. 